\title{
Kripke's metaphysical necessity: a Kantian perspective
}

Ediovani Antônio Gaboardi

gaboardi42@gmail.com

(Universidade Federal da Fronteira Sul, Santa Catarina, Brasil)

\begin{abstract}
This article studies the concept of necessity in Kripke's Naming and Necessity. Kripke distinguishes metaphysical from epistemological necessity. So, neoclassical and neoempiricist positions are both wrong, because they remain in the epistemological realm. In Kripke, the epistemology becomes a psychological investigation about individual knowledge. It cannot deal with the problem of justification, and therefore cannot explain why there are necessarily true propositions. When he tries to do this, he falls into the trap of dialectics, as Kant warned. Finally, the article defends that the metaphysical domain is just an abstraction based on an objective epistemology.
\end{abstract}

Keywords: Kripke; Kant; metaphysics; epistemology; necessity.

DOI: http://dx.doi.org/10.11606/issn.2318-9800.v26i1p33-48

\section{Introduction}

Kripke's Naming and Necessity (1980), based on his lectures at Princeton University in 1970, challenges the Kant's doctrine of a priori, a posteriori, necessity, and contingency. Its theses problematize the Kantian point of view and reintroduce the possibility of metaphysics inquiries in the philosophical field.

This article tries to show that the distinction between metaphysics and epistemology is Kripke's main strategy for sustaining the existence of necessary $a$ posteriori judgments and contingent a priori judgments. However, this distinction is based on a misunderstanding of Kant's objective epistemology and overlooks Kant's criticisms of the metaphysics' claim to know the world itself.

Besides, this text defends that the distinction between metaphysics and epistemology has serious consequences that can restrict or even deny some epistemological or metaphysical claims. If a priori judgments are not automatically necessary, what is the basis of mathematics? How can the concept of epistemology assumed by Kripke deal with the problem of justification? On the other hand, how can 
Kripke defend the necessity of certain judgment? His theory of naming can provide a sufficient basis for this?

\section{The debate about necessity and apriority}

In Necessity and apriority, Barnes (2007) uses the term "classic" to denominate the view of Leibniz, Kant, and Whewell about the relationship between necessity and apriority. According to this view, "knowledge of necessity must be a priori since the senses alone are inadequate to justify a claim of necessity. The senses tell us what the case is, but not that it must be the case" (2007, p. 496). However, Barnes states that "the classical view is now widely rejected, ever since Saul Kripke and Hilary Putnam discovered that there are propositions that are both necessary and $a$ posteriori" (idem, ibidem).

According to him, the debate concerning the epistemology of necessary $a$ posteriori truths has recently generated two views: the neoclassical and the neoempiricist. The first one, represented by Sidelle (1986), Bealer (1987), Chalmers (1996), and Jackson (1998), holds that "our knowledge of every necessary truth depends on at least one item of a priori knowledge" (Barnes, 2007, p. 496). The second one, represented by Block and Stalnaker (1999), holds that "knowledge of necessity is possible without a priori knowledge" (Barnes, 2007, p. 496).

Barnes' article can be included in the neoclassical view. He tries to prove "that knowledge of necessity requires that we have some a priori knowledge" (Barnes, 2007, p. 496). His argument is basically this:

a) Premise 1: "if there is no good empirical explanation of our knowledge of necessity, then it would seem that our knowledge of necessity requires that we have some a priori knowledge" (2007, p. 499);

b) Premise 2: "necessity is simply not among the contents of our sense experiences, even on the most liberal interpretation of those contents. Therefore, if we consider only the contents of our sense experiences, without any further cognitive processing, then the truth of a belief in necessity would have to be deemed accidental" (2007, p. 500);

c) Conclusion: "So if we do have knowledge of necessity, then this gives us strong reason to believe that we have some a priori knowledge" (2007, p. 521).

This argumentation can be persuasive, but it cannot offer an appropriate response to the Kripke's thesis. The reason is that it does not face the main strategy of Kripke's approach to the relationship between a priori and necessity: the distinction between epistemology and metaphysics. Therefore, it is useless to demonstrate, as Barnes does, that we cannot know the necessity on the basis of sense experiences. Kripke could just repeat what he wrote in Naming and Necessity: "I am concerned 
with here is a notion [of necessity] which is not a notion of epistemology but of metaphysics" (1980, p. 35). In the metaphysical context, to be necessary has nothing to do with being known a priori, just because the question about knowledge cannot even be formulated here. In the metaphysical domain,

we ask whether something might have been true, or might have been false. Well, if something is false, it's obviously not necessarily true. If it is true, might it have been otherwise? Is it possible that, in this respect, the world should have been different from the way it is? If the answer is "no", then this fact about the world is a necessary one. If the answer is "yes", then this fact about the world is a contingent one (1980, pp. 35-6).

For Kripke, necessary is any fact that happens in all possible worlds, no matter if there is someone to know it. That is, necessity is the modality related to the existence of the things, not the knowledge about them. As Kripke insists, "this in and of itself has nothing to do with anyone's knowledge of anything” (1980, p. 36). For example, if the speed of light in the vacuum is necessarily (in a metaphysical sense) equal to c (approximately $300,000 \mathrm{Km} / \mathrm{s}$ ), then in all possible worlds this will be the speed of light in the vacuum, even if there is no one to measure it.

Kripke offers the following example:

Consider, say, Fermat's last theorem - or the Goldbach conjecture. The Goldbach conjecture says that an even number greater than 2 must be the sum of two prime numbers. If this is true, it is presumably necessary, and, if it is false, presumably necessarily false (1980, p. 36$)$.

The Goldbach conjecture cannot be contingently true or false. Either each number greater than 2 is equal to the sum of two prime numbers, or not. In this view, the Goldbach conjecture concerns a mathematical fact. If the conjecture is true, the fact necessarily occurs, that is, it is the case in all possible worlds. The Goldbach conjecture, if true, expresses a necessary relationship among numbers, not a necessary relationship between human beings and the mathematical world, in the sense that all individuals know it.

In fact, we do not know that. Even today we do not know if the Goldbach conjecture is true or false. For Kripke, this means that we do not have any a priori knowledge about it. But the mathematical fact, whatever it is, "exist" and it is necessary in the "mathematical world". Perhaps in the future we will find out what the case is, and then our knowledge of it will be a posteriori, although the fact is necessary. According to Kripke's approach, this shows that the metaphysical necessity must be distinguished from epistemological apriority.

Kripke states not only the existence of necessary a posteriori truths but also of contingent a priori truths. Kripke cites the examples introduced by Kant, "gold is a yellow metal" (Kripke, 1980, p. 39), and by Wittgenstein, "one meter is to be 
the length of $S$ where $S$ is a certain stick or bar in Paris" (Kripke, 1980, p. 54). For Kripke, both are a priori but contingents. It is possible to postulate a world where the gold is not a yellow metal, and the bar of Paris is not one meter long. In the case of the standard meter in Paris, we know, for example, that a bar, in different temperatures, will be longer or shorter. Moreover, even if we do not know this fact, we could imagine a world where something like this happens.

The difference between metaphysical and epistemological approaches allows Kripke to talk about the world beyond what we know, and to compare it with what we currently know. Using this resource, Kripke can show a priori truths that are not metaphysically necessary and a posteriori truths that are metaphysically necessary.

Accepting the difference between metaphysical necessity and epistemological apriority, the argument of the neoclassical view becomes obsolete. Even if the sensory experience cannot provide knowledge of necessary truths, it does not imply that the metaphysical necessity does not exist in reality, although it is not known. Apriority and necessity, in Kripke's approach, become concepts totally not related to each other's. The modality (necessity or contingency) of a fact has nothing to do with how (a priori or a posteriori) we know it. It is possible to be born knowing (apriority) some contingent fact or never to discover a necessary fact.

Therefore, the dispute between neoclassical and neo-empiricist views about necessity is pointless, because they are epistemological positions, but the Kripkean necessity refers just to the metaphysical realm, and, as Kripke overstresses, they are "two different domains, two different areas, the epistemological and the metaphysical" (1980, p. 36). For that reason, we need to reflect on the novelty introduced by Kripke: the metaphysical necessity.

\section{Naming produces the metaphysical necessity}

Kripke refers to the metaphysical dimension through the notion of possible worlds. As Kripke emphasizes, "a possible world is given by the descriptive conditions we associate with it. [...] 'Possible worlds' are stipulated, not discovered by powerful telescopes" (Kripke, 1980, p. 44). In other words, we do not know all the possible worlds. Yet, we can stipulate how they should be. To achieve this, we use the descriptive conditions entailed by our current knowledge. When we are talking about the epistemological dimension, we are investigating how we can discover what the world is. However, in the metaphysical dimension, we are thinking about the implication of the descriptive conditions implicit in our language for all possible worlds.

In Naming and Necessity, the names play a fundamental role to access the metaphysical domain. They set up the descriptive conditions that allow talking 
about others possible worlds. They can do that because "names are always rigid designators" (1980, p. 58), and something is "a rigid designator if in every possible world it designates the same object" (1980, p. 48). A name refers determinate thing that is the same in all possible worlds where it exists. Therefore, the names fix the transworld identities that we can use to access all possible worlds where they occur. "Meter", for example, "designate rigidly a certain length in all possible worlds, which in the actual world happens to be the length of the stick $S$ at t0" $(1980$, p. 55).

For Kripke, names are rigid designators because the descriptions that we associate with them are not their meaning: "we merely use the description to fix the referent" (1980, p. 57). A referent is a determinate person, object, fact, etc., that we can access with the names of our language, but it can also exist in other possible worlds. This process allows associating other descriptions with those names. For example, "Meter" is a certain length, always the same in all possible worlds. However, it is easy to think about worlds where the length of that stick $S$ is not equal to one meter.

Through this method, we can stipulate other possible worlds by accessing the metaphysical dimension of which Kripke is speaking. The possible worlds are all the descriptions we can associate with the referents of the names of our language. To investigate the metaphysical necessity means to ask ourselves which descriptions are necessarily associated with them. That is the core of Kripke's thesis: naming produces metaphysical necessity.

The necessary descriptions of a name are the essential properties of its referent. For example, Aristotle might not have taught Alexander, and Nixon might not have been President of USA. However, according to Kripke's conclusions, is metaphysically necessary "that light is a stream of photons, that water is $\mathrm{H} 2 \mathrm{O}$, that lightning is an electrical discharge, that gold is the element with the atomic number 79" (1980, p. 116).

Concerning this last fact, according to Kripke, scientists have discovered the essential properties of gold. Therefore, in any possible world where gold exists, the gold will be the element with atomic number 79, since this property forms "the basis of what the substance is" or "it is part of the nature of gold" (1980, p. 125). If this property is not present, there is no gold.

Kripke is not talking about definitional equivalences. That is why the names can be changed. Nixon might not have been called "Nixon", but the essential properties of this man must be the same in all possible worlds. The naming is an "initial baptism" that happens in this way:

The object may be named by ostension, or the reference of the name may be fixed by a description. When the name is "passed from link to link", the receiver of the name must, I think, intend when he learns it to use it with the same reference as the man from whom he heard it (1980, p. 96). 
The name provides access to the referent using ostension or description. However, when we get the referent, we can leave the ostension, the description, and even the name. We can create a new name, for example. And, when we think about the referent, we can stipulate the properties that it must have in all possible worlds. That is the metaphysical realm.

But what Kripke thinks about epistemology?

\section{The subjective epistemology and its consequences}

As shown above, Kripke introduces the notion of epistemology when he talks about a priori. For him, "the notion of a prioricity is a concept of epistemology. I guess the traditional characterization from Kant goes something like: a priori truths are those which can be known independently of any experience” (1980, p. 34). But this possibility can only be investigated if we specify the knower: "And possible for whom? For God? For the Martians? Or just for people with minds like ours?" (1980, p. 34). That is, he relates the a priori to a particular cognitive act, performed by an individual psychological subject. Thus, a truth is a priori if an individual acquires it independently of any experience. In this case, the role of epistemology is precisely to analyze if the knowledge of a particular individual has been acquired through experience (a posteriori) or without appeal to it (a priori).

From this point of view, Kripke criticizes the traditional interpretation of the a priori knowledge. For him, "some philosophers somehow change the modality in this characterization from can to must. They think that if something belongs to the realm of a priori knowledge, it couldn't possibly be known empirically" (1980, p. 35). In other words, he thinks that what can be known without experience, can also be known empirically. Kant would have argued we can know certain things a priori, but not that we must know these things a priori, and there is no reason to change the modality from "can" to "must". Some people will know them a priori, while others will know them on the basis of experience. That means, in Kripke's approach, a priori and a posteriori have nothing to do with the nature of a specific piece of knowledge, but only with how a particular individual acquires it.

This point of view is especially interesting when he talks about mathematics. Normally we consider mathematics an a priori knowledge. For Kripke, this is not necessary. For example, someone can make the calculations to know if a number is prime, but another person can use a calculator. "So 'can be known a priori' doesn't mean 'must be known a priori" " (1980, p. 35).

This argument suggests that a mathematical truth can be a priori or a posteriori depending on how the individual apprehended it. For someone it will be a priori, for others, it will be a posteriori. In fact, for the same person, it may be a priori or $a$ 
posteriori in different times and cognitive acts. For example, we can learn that 235 multiplied by 45 equals 10575 of a calculator. After, we can do the calculations and find out for ourselves. In the first case, it will be a posteriori, while in the second case it will be a priori.

However, if the a priori and a posteriori are just two different ways how we can learn something, they cannot be used to determine its necessity, that is, if something is necessarily true or not. For our philosophical tradition, mathematical propositions are necessary because they are a priori, either in a synthetic (Kant) or in an analytical sense (Russell and the other logicists). When Kripke separates the $a$ priori and the necessity in two different domains, he attacks the very foundations of mathematics. From a metaphysical point of view, it will be still possible to say that there are necessary mathematical truths. However, we no longer will be able to determine whether this or that particular mathematical proposition is necessarily true or false. That is because the a priori, in Kripke's approach, is just a psychological phenomenon: an individual discovers something without appealing to the experience.

Someone may argue that Kripke does not want to deny the mathematical truths or the possibility to know them a priori. He only would intend to show that the necessary truths can also be known a posteriori. However, when Kripke does this, he reduces epistemology to a psychological inquiry concerning the acquisition of knowledge. Epistemology can no longer study the nature of the mathematical propositions to determine whether they are necessarily true or false. In other words, epistemology can no longer deal with the question of the justification of mathematical knowledge. Even if we know something a priori, we cannot claim we have a necessary truth, because, according to Kripke's thesis, apriority and necessity concern different questions or domains.

\section{Kant's objective epistemology}

The preoccupation with the epistemic justification is one of the most important motivations of Kant's Critique of Pure Reason. Hume (1997) produced skeptical results by demonstrating that our knowledge of the world originates from empirical experience. Kant accepts Hume's criticism of metaphysics. However, he tries to avoid this general skeptical consequence through the distinction between to commence with the experience (mit der Erfahrung anheben) and to arise from experience (aus der Erfahrung anheben): "But although all our cognition commences with experience, yet it does not on that account all arise from experience" (1998, p. 136, B1). According to Kant, there are a priori elements (space, time, and categories) that do not arise from experience and are capable of giving our knowledge universality and necessity. 
Is Kant describing how each particular individual knows something in all possible circumstances? Of course not. This issue becomes clear when we read the following passage from Kant's Lectures on Logic:

One can distinguish cognitions, then,

1. according to their objective origin, i.e., according to the sources from which alone a cognition is possible. In this respect all cognitions are either rational or empirical;

2. according to their subjective origin, i.e., according to the way in which a cognition can be acquired by men. Considered from this latter viewpoint, cognitions are either rational or historical, however they may have arisen in themselves. Hence something that is subjectively only historical can be objectively a cognition of reason. (1992, pp. 535-536, A22).

As we can see, Kant introduces two ways of classifying cognitions (Erkenntnisse): according to their objective origin (objectiven Ursprunge) or according to their subjective origin (subjectiven Usprunge). The latter corresponds to the concept of epistemology as Kripke understands it. The main question here is whether an individual has learned something by himself or through another source. For Kant, in the first case his knowledge will be rational; in the second will be historical. In Kripke's epistemology, this corresponds to a priori and a posteriori respectively.

Therefore, we can say that Kant has taken into account the fact that Kripke is considering: the possibility of learning something like mathematics through experience (through the testimony of someone, through a calculator, etc.). As Kant states,

Cognitions of reason are opposed to historical cognitions. The former are cognitions from principles (ex principiis), the latter cognitions from data (ex datis). - A cognition can have arisen from reason and in spite of that be historical, however, as when a mere literator learns the products of someone else's reason his cognition of these products of reason is then merely historical, for example (1992, p. 535, A22).

We can learn that 7 plus 5 equals 12 from our teacher, but this does not change the epistemological status of mathematics, which is for Kant a rational knowledge based on principles. We are just talking about how real people acquire knowledge, not about some inner feature of that knowledge. The cognition will be subjectively historical, but objectively rational.

A subjectivist epistemology can investigate if a particular individual has acquired knowledge from his reason or data. However, this is not the task of the 
Critique of Pure Reason, where Kant introduces the concept of a priori (and $a$ posteriori). The Critique investigates the objective origin of cognition. In his words, "we have explained cognitions of reason as cognitions from principles, and from this it follows that they must be a priori" (1992, p. 536, A23).

Against Kripke's interpretation, mentioned above, it is clear the modality of Kant's statement. He uses "must" (müssen), not "can" (können). The reason is that Kant accepts Hume's criticism of the classical metaphysics. He knows that it is not possible to construct universal and necessary judgments on the basis of experience. Their objective foundations can only be the inner principle of reason. Thus, universal and necessary judgments can only be a priori, that is, originating from the principles of reason.

According to Haddock, the Kripkean thesis about a posteriori mathematical statements "is based on a confusion [...] between 'being grounded on experience' and 'having its origin in experience"” (2012, p. 293). Following the Kantian tradition, for him "a statement is a posteriori if its truth (or falsity) is not merely known by us empirically, but moreover, if our knowledge of its truth (or falsity) is essentially dependent on experience - in the sense that it could not have been obtained by other means" (idem, p. 294). In other words, we cannot justify any answer to any mathematical question on the basis of experience. The Kantian epistemology deals just with the question about the justification of knowledge, that is, the objective origin of a cognition. And it is just in the realm of objective epistemology where Kant introduces the concept of a priori (and a posteriori).

In turn, Kripke uses the concepts of a priori and a posteriori in a very different sense, as Haddock points out (2012, p. 294). From a Kantian point of view, Kripke is saying that cognitions can be rational (a priori) or historical (a posteriori). However, both cases refer to their subjective origins, and that is not the place to talk about necessity or contingency.

\section{The Kantian denial of the metaphysical pretension of formal logic}

Kant not only argues that some kinds of knowledge, such as mathematics, has an objective basis, but he also intends to establish, following Hume, the limits of our a priori knowledge. That can be understood especially in his classification of logic. According to Kant (1998, p. 194, B76), it can be divided into general logic and particular logic. The former, also called elementary logic, concerns the necessary rules of thinking, regardless of any subjects. The latter, also called organon, investigates the rules we use when we think of certain types of objects.

The general logic has just one principle: the non-contradiction. It is elementary because it is the basis of any other use of the understanding. Particular logic, in 
turn, investigates the formal rules of a given field of knowledge (e.g., physics). It is also formal, but it addresses the judgments of a particular area of study. It is an organon, that is, an instrument that helps a given scientific discipline to form itself, formalizing or even axiomatizing its essential foundations or presuppositions. However, it is important to realize that, although it focuses on the foundations of a science, it must emerge at last. It only formalizes, clarifies and gives rigor to a knowledge that has already been acquired from another source. In other words, no knowledge can be drawn from logic, even a particular one. It can give form (logic) to knowledge already possessed, but it cannot tell how the world is or could be.

Continuing his classification, Kant states (1998, pp. 194-5, B77) that the general logic can be pure or applied. In the first case, the general logic is a canon, that is, a set of formal rules that arise from the principle of contradiction, which govern the working of pure understanding. In the second case, the general logic is a cathartic of the common understanding, that is, an application of the general rules on the understanding of an empirical subject, which can be influenced by prejudices, inclinations, and so on. The precise purpose of the latter is the catharsis, the "purification" of the empirical subject. In this way, he can avoid fallacies and judge based exclusively on the pure general rules of understanding.

By these assumptions, Kant indicates (1998, pp. 198, B84-5) two possible uses of general logic: the analytics and the dialectics. Analytics is the correct use of general logic. Why is it correct? Because it is limited to the form of judgments, without intending to determine something about its content. It is a negative touchstone (Probierstein) of the truth of judgments. That is, by analyzing a judgment, one can verify whether it is contradictory or not. If it is, it cannot be true. If it is not, it can be true or false. However, the general logic cannot either produce judgments or provide positive criteria for deciding which judgment is true. To produce judgments about objects, as Kant says, one has to get out of logic to obtain information. Only then it will be possible to connect different pieces of information and see if the resultant judgments are contradictory or not.

On the other hand, dialectics is precisely this pretension to learn something about the actual world from the general logic. In this case, the general logic becomes an organon, that is, a tool to know something. However, as Kant advises, "the dialectics is the logic of illusion - a sophistical art for giving to its ignorance [..] the air of truth" (1998, pp. 198, B86). The dialectics produces the illusion that it is possible to say something about the world on the basis of the laws of logic.

This point is important for two reasons: first, it shows that Kripke's interpretation about the Kantian example, "Gold is a yellow metal" as an a priori but contingent truth, is unfair; secondly, it shows the dangers of trying to say something about the world on the basis of logic. 
On the first point, Kant indeed suggests that "Gold is a yellow metal" is an $a$ priori judgment. Moreover, we also need to agree with Kripke when he shows that the gold is not necessarily a yellow metal. However, we must understand the context of Kant's statement. When Kant uses this example, in Prolegomena, he is addressing the difference between analytic and synthetic judgments. He shows that "the predicate of an affirmative analytic judgment is already thought beforehand in the concept of the subject, it cannot be denied of that subject without contradiction" (2004, p. 17, A25-26). In other words, when we assign a predicate to a concept that implicitly already contains it, we are producing an analytic judgment, and this judgment is $a$ priori.

However, this does not imply that we know the meaning of all the words of this judgment without any experience. For Kant, this is impossible. We need the experience to know what gold, metal, and yellow are. A priori is just the connection between gold and yellow metal. However, this connection is only possible once we know the meaning of these concepts. In this case, when we say, "Gold is a yellow metal", we are only explaining the meaning of gold we learn from experience. As Kant states,

For that reason all analytic propositions are still a priori judgments even if their concepts are empirical, as in: Gold is a yellow metal; for in order to know this, I need no further experience outside my concept of gold, which includes that this body is yellow and a metal; for this constitutes my very concept, and I did not have to do anything except analyze it, without looking beyond it to something else (2004, p. 17, A26).

As we can see, in this example Kant assumes that Gold is a yellow metal. This information comes from experience, that is, Gold is an empirical (a posteriori) concept. If we already know what Gold is, the judgment, "Gold is a yellow metal", does not add any information. Therefore it is analytic, not synthetic, and, for the same reason, it is a priori.

Making it clear, Kant is not saying that the empirical concept of Gold is $a$ priori and necessary. We need to learn what Gold is from experience, not from pure reason. The logic only shows the relationship between the concepts we already have. It cannot produce these concepts.

On the second point, we must remember the Kripke's thesis presented above: "Gold is an element with atomic number 79" is a metaphysically (not scientifically) necessary truth. In all possible worlds where gold exists, that is its nature. However, how can Kripke justify this statement?

The answer should be the Kripkean theory of naming. The naming produces necessity. However, how can a theory about the language determine whether a proposition is true or false? Apparently, Kripke's theory of language has become a 
tool (organon) to know something about the world. That means Kripke fell into the trap of dialectics, as Kant warned. He wants to say something about the actual world beyond all possible experience.

According to Kant's Critique, that is impossible, as we have seen above. But there is another argument against this claim of the Kripkean theory of naming. We must remember that Kripke, at least in Naming and Necessity, reduces epistemology to a psychological approach, denying its capacity to offer any approach to justification. So, it is impossible for him to say that a specific object, like "an element with atomic number 79", is the adequate referent to the name "gold". Because to say that is the same as saying that the proposition "Gold is an element with atomic number 79" is true. But, if epistemology is just a psychological investigation about how we learn, it cannot offer sufficient justification for any proposition. Without fulfilling this epistemological task, any naming will be arbitrary, in the sense that we will not know what the referent of the name is.

\section{Metaphysical versus epistemological necessity}

As we can see, the basis of Kripke's theses in Naming and Necessity is the distinction between metaphysical necessity and epistemological apriority. This distinction gives him the chance to propose the existence of a posteriori necessary and $a$ priori contingent truths.

But let's think again about a passage partially quoted above, where Kripke introduces the distinction between metaphysics and epistemology:

The second concept which is in question is that of necessity. Sometimes this is used in an epistemological way and might then just mean a priori. And of course, sometimes it is used in a physical way when people distinguish between physical and logical necessity. But what I am concerned with here is a notion which is not a notion of epistemology but of metaphysics, in some (I hope) nonpejorative sense. We ask whether something might have been true, or might have been false. Well, if something is false, it's obviously not necessarily true. If it is true, might it have been otherwise? Is it possible that, in this respect, the world should have been different from the way it is? If the answer is "no", then this fact about the world is a necessary one. If the answer is "yes", then this fact about the world is a contingent one. This in and of itself has nothing to do with anyone's knowledge of anything. It's certainly a philosophical thesis, and not a matter of obvious definitional equivalence, either that everything a priori is necessary or that everything necessary is a priori. Both concepts may be vague. That may be another problem. But at any rate they are dealing with two different domains, two different areas, the epistemological and the metaphysical (1980, pp. 35-6).

As we can see, for Kripke there are many concepts of necessity: epistemological, physical, logical, and metaphysical concepts. He argues that the metaphysical is not equivalent to a priori, but admits that the epistemological is. 
Obviously, his proposal is to address the metaphysical necessity. As we have seen earlier, metaphysical necessity is a modality related to the existence of things, not to knowledge about them. Necessary is any fact that happens in all possible worlds, no matter if it is known to someone.

However, following the text, Kripke talks about "something" that can be either true, false, or both. And metaphysical necessity is taken as "something" that cannot be false. But what "something" is referring to? Facts? Beliefs? Propositions?

Obviously, facts cannot be true or false. Facts just happen (necessarily or contingently), even when we don't know them. If a fact is necessary, it occurs in all possible worlds. So when Kripke uses the concept of truth to explain the concept of necessity, he cannot be talking about facts, but about beliefs, propositions, judgments, or something like that.

Propositions, beliefs, judgments, etc. are claims of knowledge. If the fact which a proposition, for example, describes does happen, the proposition is true. Otherwise, the proposition is false.

But what does it mean to say that a proposition is necessarily true? It means we have sufficient proofs to state that the proposition is true and cannot be false. This meaning is typically epistemological: it is an index of the justification status of a proposition.

But, if a proposition is necessarily true, is necessary the fact described by it, that is, does it occur in all possible worlds? If the answer is affirmative, we can say that epistemological necessity implies metaphysical necessity and that this would be the source of metaphysical necessity.

However, this is not necessarily the case. For example, I could imagine that the proposition "my dog is black" is a necessary truth, because I see my dog every day and I know what black means. Necessary truth, in this case, means something like "it is impossible that my dog is not black in the world which I am describing". I am not saying anything about the other worlds. So, the epistemological necessity cannot be the source of the metaphysical necessity.

Furthermore, modern philosophers, like Hume, were skeptical about the possibility of necessary truths in the empirical cognitive domain. Empirical experience is always insufficient to provide a basis for necessary statements. This fact does not depend on individuals. The main problem is that the senses can only capture the present, and the necessary statements are also about the future. Therefore, it is always logically illegitimate to exceed experience and talk about necessary facts. In other words, the proof of an empirical statement is always singular perceptions, but singular perceptions cannot justify statements about the future (necessary propositions). Now, a proposition or judgment whose proof is singular perceptions is called a posteriori. So it is necessary to conclude that a posteriori propositions or 
judgments are always contingent, in the sense that it is impossible to have sufficient proofs that they are true.

On the other hand, most modern philosophers agree that logic and mathematics do not have that problem, because they do not depend on experience. The proof of a logical or mathematical demonstration is the relationship among concepts in it or a pure intuition (Kant). In both cases, an empirical experience is not suitable. That is the reason why logic and mathematics are a priori. And because they are a priori, they are not conditioned by empirical experience and are necessary, in the sense that there are sufficient proofs that they are true without appealing to experience.

So, when we state that some proposition is necessarily true for logical, mathematical or similar a priori reasons (not for empirical reasons), we are advocating that it is true regardless of the world. That situation allows thinking that the proposition is true in all possible worlds because the actual world is not the basis for the truth of the proposition. But this is not because the naming allows us to postulate a metaphysical realm. It is just an effect of the way the proposition was justified. In the case of propositions with empirical content, an a priori justification is only an analytical procedure based on the names we take as a starting point. And it is sometimes possible to change the meaning of these names based on changes in our understanding of the empirical world.

Consequently, we must admit that "necessarily true" is just an epistemological notion, not a metaphysical postulate. It describes the justification status of a proposition when we have sufficient reason to state that it cannot be false. And, how Kripke admits, in its epistemological meaning, necessity is the same of a priori.

\section{Conclusion}

The first conclusion of this article is that we cannot disregard the distinction between epistemology and metaphysics when we discuss apriority and necessity in Kripke. This distinction makes both neoclassical and neo-empiricist views irrelevant. Kripke does not claim he has discovered a method for knowing necessary truths from experience. He only argues that necessary truths exist, even if they are known $a$ posteriori. So, if we want to reject the conclusion of Kripke's argumentation, it is useless to reject the empiricism as a way of acquiring some necessary knowledge. We need to face the distinction between metaphysical and epistemological spheres because it is the basis of Kripke's theses.

Kripke's distinction between metaphysics and epistemology gives him the possibility to defend the existence of the a priori contingent and the a posteriori necessary judgments. However, there is a price to pay, and this is the second conclusion of this article: Kripke reduces epistemology to a psychological inquiry into how a particular person knows something. After that, it is impossible to justify 
any proposition, including mathematics. Metaphysical necessity can be postulated, but it has nothing to do with necessity in the epistemological context. That is, Kripke cannot say that a particular proposition is necessarily or contingently true or false, because this kind of issue concerns epistemology, not metaphysics. Moreover, as we have seen, it concerns objective epistemology like the Kantian.

That leads to a third conclusion. Kripke states that there are certain necessary truths. For example, "Gold is an element with atomic number 79". However, how can he say that? Or rather, what meaning can this statement have when we consider the Kripke's presuppositions, especially the distinction between metaphysics and epistemology?

If Kripke's statement had an epistemic meaning, he would be saying that the proposition "Gold is an element with atomic number 79" is necessarily true. However, if he said that, he would be falling into the trap of the dialectics. As Kant has advised, we cannot use logic (or a theory about the naming) as a tool for knowing (organon).

Therefore, we should understand Kripke's statement about necessity (and contingency) exclusively in a metaphysical sense, that is, leaving aside the question of truth (and falsity). If the essential referent of the word "gold" is the "element with atomic number 79", then in all possible worlds this will be its referent. Here we have just a postulate that was built on the basis of our actual world. It does not represent any discoveries and does not add any information.

Finally, we can conclude that the metaphysical meaning of the concept of necessity is only an abstraction produced from an objective epistemological investigation. When we discover that some proposition is necessarily true, we can argue that the fact described by it occurs in all possible worlds. But this is just a postulate based on analytical procedures or our current knowledge of the world.

\section{References}

Barnes, G. (2007). Necessity and Apriority. Philosophical Studies, 132, 495-523. DOI: https: //doi.org/10.1007/s11098-005-2531-y

Bealer, G. (1987). The Philosophical Limits of Scientific Essentialism. Philosophical Perspectives, 1, Metaphysics, 289-365. DOI: https://doi.org/10.2307/2214149

Block, N. \& Stalnaker, R. (1999). Conceptual Analysis, Dualism, and the Explanatory Gap. Philosophical Review, 108(1), 1-46. DOI: https://doi.org/10.2307/2998259

Chalmers, D. (1996). The Conscious Mind. Oxford: Oxford University Press.

Haddock, G. (2012). Against the Current: Selected Philosophical Papers. Heusenstammt: Ontos Verlag.

Hume, D. (1997). An Enquiry Concerning Human Understanding. Oxford: Oxford University Press. 
Jackson, F. (1998). From Metaphysics to Ethics: A Defence of Conceptual Analysis. Oxford: Oxford University Press.

Kant, I. (1992). Lectures on Logic. Cambridge: Cambridge University Press.

Kant, I. (1998). Critique of Pure Reason. Cambridge: Cambridge University Press. [Kant, I. (1956). Kritik der reinen Vernunft. Hamburg: Felix Meiner].

Kant, I. (2004). Prolegomena to Any Future Metaphysics That Will Be Able to Come Forward as Science with Selections from the Critique of Pure Reason. New York: Cambridge University Press.

Kripke, S. A. (1980). Naming and Necessity. Harvard: Harvard University Press.

Sidelle, A. (1986). Necessity, Essence and Individuation: A Defense of Conventionalism. Ithaca: Cornell University Press.

Recebido em: 09.06.2020

Aceito em: 11.06.2021

Esta obra está licenciada com uma Licença Creative Commons Atribuição-NãoComercial-Compartilhalgual 4.0 Internacional.

https://creativecommons.org/licenses/by-nc-sa/4.0/

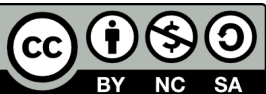

